\title{
Remote myocardium is also affected in acute myocardial infarction: evidence from advanced CMR relaxometry
}

\author{
Amardeep Ghosh Dastidar, Elisa McAlindon, Jonathan C Rodrigues, Anna Baritussio, Alessandra Scatteia, \\ Estefania De Garate, Chris B Lawton, Chiara Bucciarelli-Ducci \\ From 19th Annual SCMR Scientific Sessions \\ Los Angeles, CA, USA. 27-30 January 2016
}

\section{Background}

In patients with ST elevation myocardial infarction (STEMI), myocardial tissue injury is not restricted to the territory supplied by the culprit artery but it affects also the remote myocardium supplied by unaffected arteries.(1) The aim was to investigate the T1 and T2 characteristics in infarcted and remote myocardium comparing it with normal reference standard.

\section{Methods}

30 patients (mean age $61 \pm 10$ years and $70 \%$ males) with STEMI and successful revascularisation by percutaneous coronary intervention were included. Each subject underwent clinical CMR at $1.5 \mathrm{~T}$ with $\mathrm{T} 2$ and $\mathrm{T} 1$ mapping (MOLLI) pre and post contrast (equilibrium contrast technique for extracellular volume (ECV) quantification) within 48 hours of presentation. The T2 and pre and post contrast T1 values were evaluated in each of the 16 AHA myocardial segments.

\section{Results}

Out of 480 myocardial segments, 143 were affected and the rest unaffected or remote. The mean native T1 and the mean ECV in the remote myocardium was higher than the reference standard $(1054 \pm 65 \mathrm{msec}$ vs $950 \pm$ $21 \mathrm{msec}$ and $0.32 \pm 0.06$ vs $0.25 \pm 0.04)$. (2) However, the mean native T1 and the mean ECV of the remote myocardium was significantly lower compared to infarcted myocardium $(1054 \pm 65 \mathrm{msec}$ vs $1153 \pm 85 \mathrm{~ms}$, $\mathrm{p}<0.0001$ and $0.32 \pm 0.06$ vs $0.46 \pm 0.11 \mathrm{~ms}, \mathrm{p}<0.0001$ respectively). In addition the mean $\mathrm{T} 2$ of the remote myocardium was significantly lower compared to infarcted myocardium ( $54 \pm 5$ vs $63 \pm 7 \mathrm{~ms}, \mathrm{p}<0.0001)$.

\section{Conclusions}

This is the first study looking at the impact of STEMI on remote myocardium via non-invasive tissue characterisation by advanced CMR relaxometry technique. Our study highlights that the remote myocardium is also affected following STEMI when compared to normal. Albeit the myocardial tissue injury in the infarcted territory is significantly greater than remote myocardium. These findings may have significant future implications in the treatment of STEMI, including targeting the remote myocardium.

Published: 27 January 2016

\section{References}

1. Abbate A, Bonanno E, Mauriello A, et al: Widespread myocardial inflammation and infarct-related artery patency. Circulation 2004, 110(1):46-50.

2. Dabir D, Child N, Kalra A, et al: Reference values for healthy human myocardium using a T1 mapping methodology: results from the International T1 Multicenter cardiovascular magnetic resonance study. J Cardiovasc Magn Reson 2014, 16:69.

doi:10.1186/1532-429X-18-S1-P219

Cite this article as: Dastidar et al:: Remote myocardium is also affected in acute myocardial infarction: evidence from advanced CMR relaxometry. Journal of Cardiovascular Magnetic Resonance 2016 18(Suppl 1):P219. 